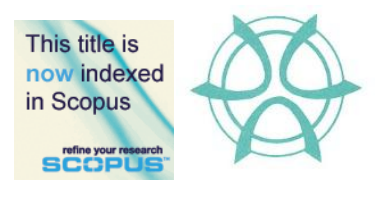

PLANNING MALAYSIA:

Journal of the Malaysian Institute of Planners

Volume XII (2014), Page59 - 80

\title{
CONCEPTUALISE TOURISM SUPPORT SYSTEM THROUGH WEB-BASED GIS FOR COLLABORATIVETOURISM PLANNING
}

\author{
Tarmiji Masron ${ }^{1}$, Azizan Marzuki ${ }^{2}$, Badaruddin Mohamed ${ }^{3} \&$ \\ Norizawati Mohd Ayob ${ }^{4}$ \\ ${ }^{1 \& 4}$ School of Humanities; ${ }^{2 \& 3}$ School of Housing, Building and Planning \\ UNIVERSITI SAINS MALAYSIA
}

\begin{abstract}
Web based GIS plays a bigrole in tourism, especially in public and management use. The popularity of Web based GIS is increasing dramatically as seen through the number of web GIS emerging over the years. Web based GIS allows professionals, organizations and the public to share and collaborate on information unhindered by geographic boundaries. The integration of GIS with the World Wide Web (WWW) brought a new paradigm of enhancing the collaborative planning effort among stakeholders. It also became a new medium of inviting public participation in planning and management processes by providing information in the form of maps and data for public access and paving the path for data sharing with agencies having the same interest. This paper aims to explore the concept of web based GIS and identify how it can be used towards enhancing collaborative planning and public participation among tourism stakeholders and communities. The Langkawi Island Web GIS is a website which provides tourism related information about Langkawi Island and allows for public participation as an information supplier.
\end{abstract}

Keyword: Web based GIS, tourism, collaborative planning \& Langkawi Island.

\footnotetext{
${ }^{1}$ Associate Professor of Geographic Information System at Universiti Sains Malaysia. E-mail: mmiji@usm.my

${ }^{2}$ Senior Lecturer at Universiti Sains Malaysia.

Email: chik72@usm.my or chik72@yahoo.com
} 
Tarmiji Masron, Azizan Marzuki, Badaruddin Mohamed \& Norizawati Mohd Ayob

Conceptualise Tourism Support System through Web-Based GIS for Collaborativetourism Planning

\section{INTRODUCTION}

The Information Communications Technologies (ICT) is inevitably making societies and cities increasingly knowledge-based (Ali, 2006). It empower consumers to identify, customize and purchase tourism products and support the globalization of the industry by providing tools for development, managing and distributing offerings worldwide. ICTs have a broad terminology referring to the multitude of communication technologies ranging from simple to the complex, namely cell phone applications (SMS), Digital Cameras, Internet, Wireless (WiFi and WiMAN), VOIP, GPS, GIS, Convergence (data, voice, and media), Digital radio, etc. Considered an information intensive industry, tourism can benefit synergistically from the use of ICT components especially the internet. The internet provides a wealth of pertinent and directly accessible information at low costs on prices, products and potential opportunities. A simple assessment of the impacts of the internet lead to the ready conclusion in the reduction of information asymmetries on the market and to the emergence of markets of pure and perfect competition (Loghi, 2008).

The internet is especially relevant to tourism since it enables knowledge gathering about the consumer or tourist products. According to Werthner \& Klien, (1999) this gives rise both to global visibility of destinations and a global merging of market segment. The use of web based tourism information system is growing significantly and is predicted to remain so in the future, with the distinct possibility of creating the whole tourism business premised on the internet. Web-based GIS has been applied in many fields, including geography, forestry, urban development and planning and environmental studies. The integration between the World Wide Web and Geographic Information System (GIS) has changed the way organizations use geographic information, as well as the process of accessing, sharing, disseminating and analyzing data (Duran, Seker, \& Shrestha, 2004). Today, the popularity of Web based GIS has shown a marked increase as seen through the emerging number of web GIS, which allows the professionals, organizations and the public to share and collaborate information unhindered by geographic boundaries. 


\section{CONCEPT AND ARCHITECTURES OF WEB-BASED GIS}

Web based GIS is a type of information system that integrates, disseminates and communicates spatial information on the internet or the World Wide Web (Gillavry, 2000; Peng \& Tsou, 2003). There are a number of various web based GIS system currently on the internet, classified based on functionalities or types of systems but the classification basis is fairly complex. The simplest classification of web based GIS can be defined into two categories based on their sources, namely single source and multiple sources. The single source system refers to the system having only one web server in providing the information while multiple source system could request data from a variety of web servers (Shaig, 2001). To develop a web base GIS, the basic approach for deploying Web based GIS application depends on the user requirements which addresses concerns of which web GIS packages are suitable to best accomplish their objective.

In developing web based GIS application, there are basically two types of architectures; first is the server-side and the second is the clientside. In server-side web GIS architecture, users (clients) are allowed to submit requests for data and analysis to the Web server. The server processes the request and returns data or a solution to the remote client (Fajuyigbe, Balogun, \& Obembe, 2007). Usually, the web GIS server combines a standard web (HTTP) server, GIS application server and the GIS database and also functionalities that reside completely on the server (Markos, 2012).

A standard Web (HTTP) server, the GIS application server and GIS databases are the common components in the Internet-GIS server, with the functionalities residing completely on the server. The design in server-side architecture allows the users to interact with the clients' machine via typed queries (requests). The user's queries are transferred to the Web server and then passed to the GIS application server, which run an address matching routine. It then generates a map graphically, convert it to the Web format, wraps the image in HTML and sends it back to the web server as a result of the user's queries. The results will emerge as a standard Web page and can be easily accessed through any web browser, creating significant positive implications for performance, reliability and size of the user base (Figure 1). Due to the complex and proprietary softwares in server-side design, as well as the GIS database residing on a server, application development in these designs for deployment and maintenance of the data can thus be simplified. However, server-side architecture is almost always associated with poor performance and limited user interface and interaction (Belay, 2005) 
Tarmiji Masron, Azizan Marzuki, Badaruddin Mohamed \& Norizawati Mohd Ayob

Conceptualise Tourism Support System through Web-Based GIS for Collaborativetourism Planning

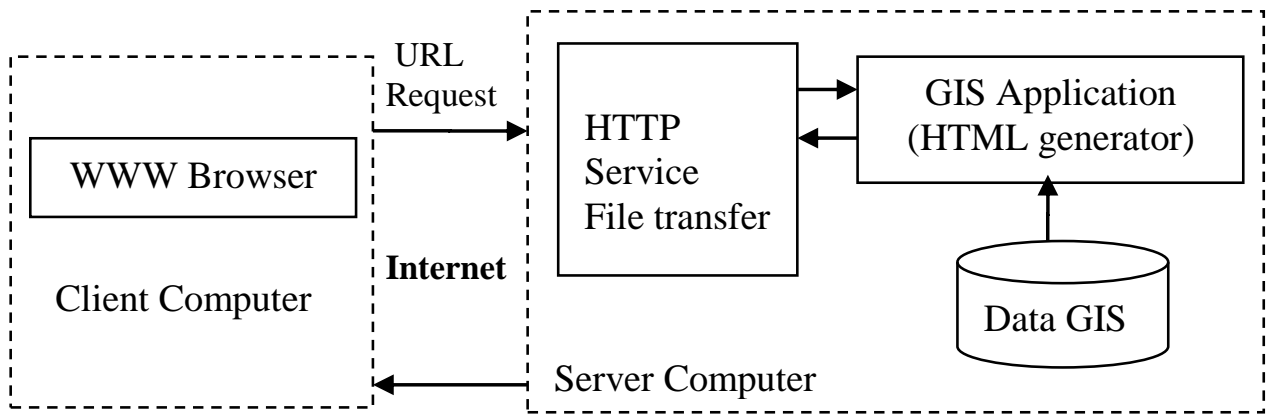

HTML Image map

Figure 5: Server-Side Architecture

Source: Markos, 2012

Client-side architecture, on the other hand allows the users to perform some data manipulation and analysis locally on their own machines. For that, users are required to install a complete client application, and in such systems, either a substantial amount of GIS functionality is moved to the client, or only the user interface is enhanced slightly to enable specific user interaction. Correspondingly, the client-side application requires software and some other than browsers to be transferred to the user (Figure 2) (Markos, 2012).

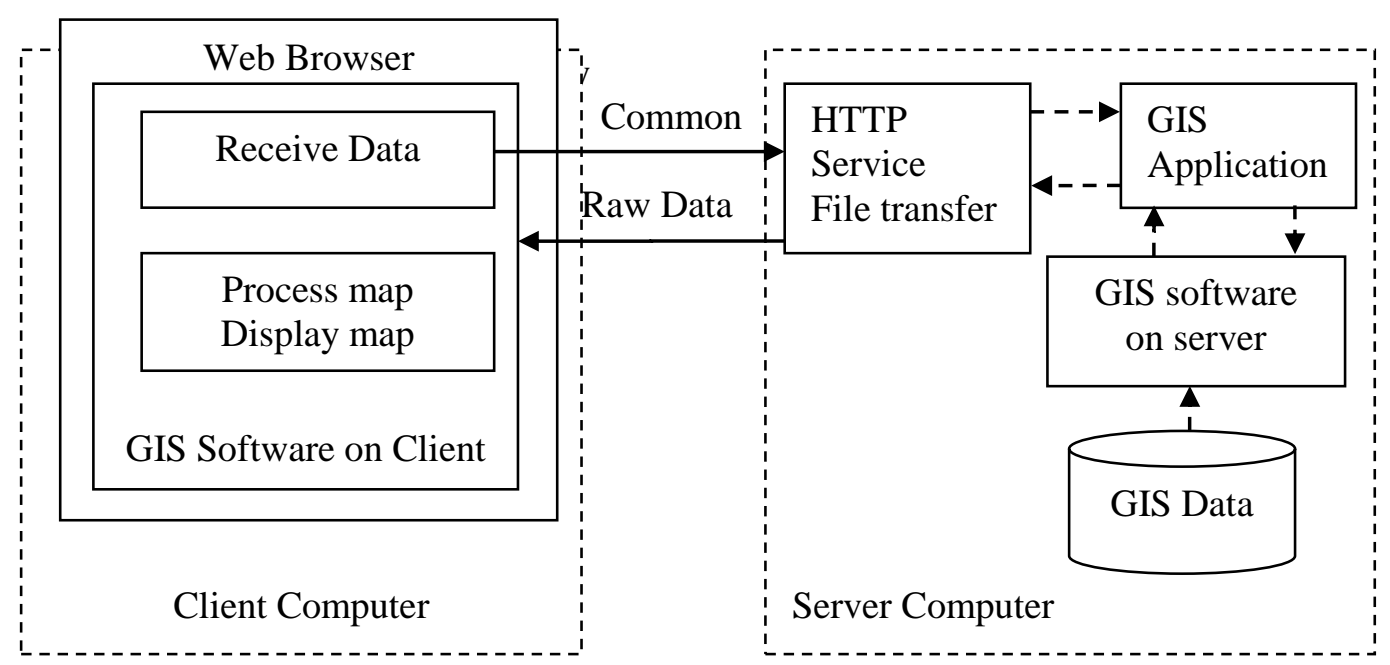

Figure 6: Client Side Architecture 
On client-side Internet-GIS, the main operation will run on the server. When the server receives inquiries from the client, it will begin communicating to the database and retrieves attributes of the map from the database. That apart, the GIS application server also has direct access to the map. The output map file could be SHP, DXF, etc and will be used to create map files like lines, points, area and also the labels. The raw map and HTML image will be provided to users via the servers (Belay, 2005). In client-side solutions however, the biggest disadvantages are the software and distributing data.

The software distribution is very problematic as it consumes the technical support to handle it which involves high cost. The combination of server side and client side architecture will create a new form of system named as hybrid or client/server architecture. This architecture is created to overcome the limitations in client-side applications and allows the user to use both (server and client) design techniques to access the GIS on the internet. Users can make the request to the web server through the web browser which will generate the HTTP request in the form of an html page like the server-side design or access GIS data from the Internet. The process occurs through the users' own GIS packages which will enable manipulation on the client system (Figure 3). Generally, the server tasks in hybrid architecture can be simplified into four main activities - map browsing, query, analysis and map drawing. For client-side architecture, the task is for display, map browsing and query.

Client Side

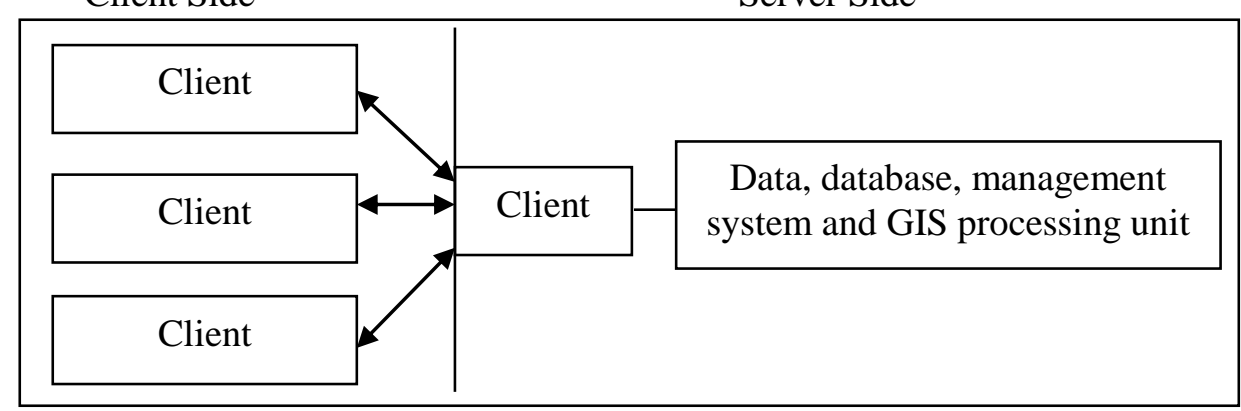

Figure 7: Hybrid Architectures

Source: Belay, 2005 
Tarmiji Masron, Azizan Marzuki, Badaruddin Mohamed \& Norizawati Mohd Ayob

Conceptualise Tourism Support System through Web-Based GIS for Collaborativetourism Planning

Geographic Information Systems (GIS) are now widely recognized as a valuable tool for managing, decision making, analyzing, and displaying large volumes of diverse data pertinent to many local and regional planning activities (Avdimiotis \& Christou, 2004). The combination of GIS and webbased applications which contained spatial attributes has evolved to become more than a program since GIS is a visual and analytical tool and helps users understand or visualize this information in a map and enables the users to manage this information interactively and analytically. The developments in Web-based GIS make it a distinct feature with high inter-activity and strong end-user participation (Chang \& Caneday, 2011).

\section{WEB-BASED GIS AS MEDIUM OF COLLABORATIVE PLANNING AND PUBLIC PARTICIPATION}

In 1996, after the meeting of the National Center for Geographic Information System and Analysis the term 'public participation geographic information systems' was conceived. The concept of using GIS technologies was to produce local knowledge with the purpose of including and empowering the marginalized population (Brown \& Reed, 2009). The integration of GIS with the World Wide Web (WWW) brought about a new paradigm in enhancing the collaborative and community participation aspects in planning. It was applied to many sectors as one of the medium to help stakeholders to create a more effective planning and decision making process involving public participation.

Citizen participation is widely viewed as a key component in the planning process, and for the most part, planners accept the notion that participation is important to producing enduring plans (Brody, Godschalk, $\&$ Burby, 2003). But effective participation involves a two-way process that includes sending information out to the public and getting their ideas, concerns and thoughts back (Godschal, Parham, Porter, Potapchuk, \& Schukraft, 1994). In the traditional approach, due to aspects of venue, time, cost and the delivery mechanism, active participation was considered a failure as public participant meetings were dominated by small, disproportionately vocal groupsl; many individuals were hesitant to express their concerns and opinions (Healey, McNamara, Elson, \& Doak, 1988).

Web-based GIS offers an effective approach in getting a wider range of opinions and information at lower cost because of its online system that can be used by the public anywhere and anytime as long they have access to the web. Web based GIS provides all of the functions, allowing users to 
explore, evaluate, prescribe and discuss planning and policy issues within the community. An application GIS for public participation includes features that cover the community economic development, environmental dispute resolution, participatory planning, and other activities involving public collaboration. Technologies chosen or developed to support this approach can be designed to document and record the problem resolution process, allowing evolving priorities and problem definitions to be tracked by all participants (Banger, 2002).

Based on the different levels of contents and functionality, web based GIS for the collaborative and public participation processes could have various phases of services which involve the different degree of public participation and user interactions. The lower level services represent the lower requirement of public participation, and accordingly, the highest levels of services represent the highest requirements. The generalization of frameworks of the system and the level of service categories can be designed based on information content (general information, plan alternative, data, analysis tools) and interface functionality (web browsing, static map [clickable maps], interactive map-based search, query, and analysis and Scenario building and on-line editing). The different levels of functionality also require different types of system architectures. In ways to support high involvement of public participation using web based capabilities, a three-tier architecture is required premised upon a hybrid design (Figure 4). This architecture comprises the web browser (client tier), web server (server tier) and one or more server application (application tier) (Peng \& Tsou, 2003).

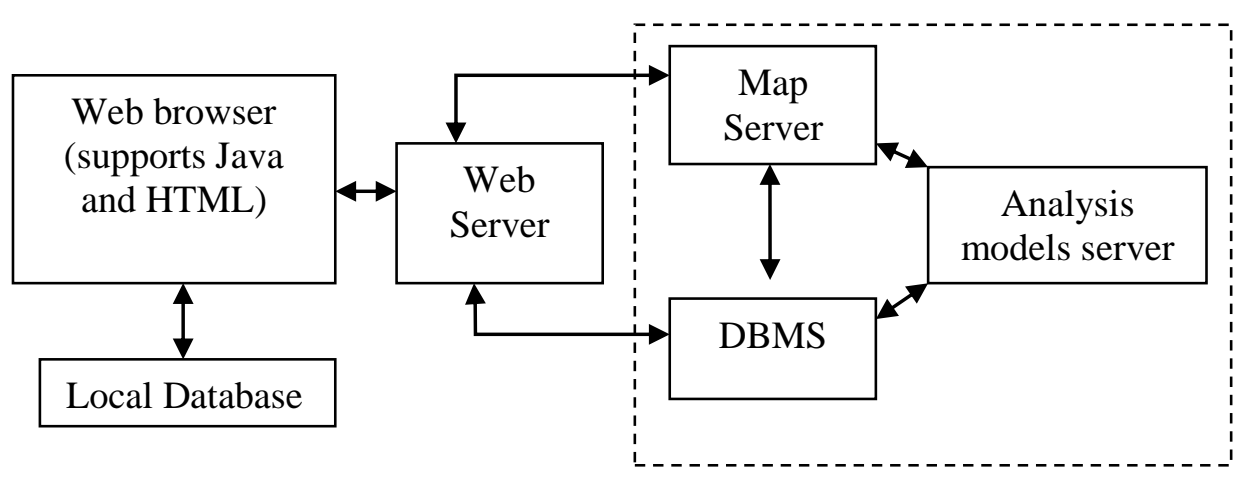

Figure 8: A three-tier Architecture for Internet GIS-based Public Participation Source: Peng Z.-R. , 2001 
Tarmiji Masron, Azizan Marzuki, Badaruddin Mohamed \& Norizawati Mohd Ayob

Conceptualise Tourism Support System through Web-Based GIS for Collaborativetourism Planning

Therefore, in enhancing public participation, web-based GIS could be a medium of specific information sharing that enables and supports efforts to view as well as retrieve information at different time and places (Devaraju, Nanna, \& Shahrin, 2007). Web-Based GIS is a medium inclined more towards inviting public participation, apart from providing information in the form of maps and data for public access, and paving the path for data sharing with agencies having the same interest. A component of Web-based GIS Public Participation System consists of map viewer and web content management, which will be used for the public in giving their opinion or information. The map viewer which includes basic functions such as pan, zoom, select, identify and custom search tool, will allow the user to submit their views or suggestions on the tourism product. The tools menu contains functions such as edit, draw and print and can be used for general purposes. Edit function allows users to add point features (objects) or edit information (Attribute data) of existing point features in the Web GIS.

The application of web based GIS for collaboration and public participation was used broadly to support the decision making process in many fields included in urban planning and management research (Yaakup, Jama'an., Abu Bakar, \& Sulaiman, 2001; Ventura, Niemann, Sutphin, \& Chenowith, 2002; Belay, 2005; Devaraju, Nanna, \& Shahrin, 2007; Kingston, 2007); environmental planning and management (Kingston, Carver, Evans, \& Turton, 2000; Carver, Evans, Kingston, \& Turton, 2002; Nuohua, Juustila, Raisanen, Kuutti, \& Soudunsaari, 2008); social research (Casey \& Pederson, 2002; Al-Kodmany, 2002); and environment and public health (Devictor, Whittaker, \& Beltrame, 2010). Other than that, the tourism industry is one field that uses Web based GIS intensively in ways to plan, manage and promote tourism products in most destinations around the world.

One of the earliest public participation using GIS was originated in mid-1990s by Onsrud, Schroeder and Lopez of the University of Maine. Based on their workshop on how to improve access to GIS among nongovernmental organisations and individuals involved with public policy making, public participation GIS (PPGIS) has been used to come up with tools for spatial decision-making (Schroeder,1997). A Collaborative planning and public participation Web GIS enables people to express their views by posting comments in a relatively anonymous and nonconfrontational manner (Meng \& Malczewski, 2010).

Nevertheless, even after Web GIS technologies were used for collaborative planning and public participation, the feedback from local community members sometimes is quite unsatisfying. According to Lee 
(2000), about $34 \%$ of all users visit the website with GIS application on a monthly or occasional basis. Study by Hopkins et al. (2004) found that some users just give up in the middle of the involvement process because of learning barriers and complicated interfaces, while some projects end up with only few number of participants (Sidlar \& Rinner, 2007; Ingensand \& Golay, 2010).

In relation to the above issues, Meng \& Malczewski (2010) suggest that Web GIS designers should focus on refining the system features, such as navigating the Web site, locating desired documents, and enhancing content; design functions that work with standard Web browsers; and choose the right resolutions to attract users to stay longer on the Web site and interact more with others. The idea is to ensure users will visit the Web sites more frequently, view more pages, and interact more often with other participants.

\section{THE COLLABORATIVE PLANNING AND PUBLIC PARTICIPATION USING WEB-BASED GIS FOR TOURISM PRODUCT}

In the tourism industry, information in various fields is necessary for tourists to make informed decisions but it is rather difficult or nearly impossible to pull all the information together and make sense of them. Besides that, tourism development is also related to many other industries such as accommodation, transportation, leisure, services and hospitality (Wilkinson, 2007; Gu \& Ryan, 2008). Today, Web based GIS plays a decidedly important role in tourism, especially in public and management use which have raised several key questions by public and managements users as shown in Table 1.

Table 11: Question by Public and Management User on GIS System

\begin{tabular}{ll}
\hline Public User Questions & Management User Questions \\
\hline $\begin{array}{l}\text { Where is the city, state or country } \\
\text { located? }\end{array}$ & $\begin{array}{l}\text { What are the areas that tourists are interested to } \\
\text { visit? }\end{array}$ \\
\hline $\begin{array}{l}\text { What is the climate? Does it have } \\
\text { warm or cold weather? What is } \\
\text { the best time of year to visit? }\end{array}$ & \\
\hline $\begin{array}{l}\text { What is the official language } \\
\text { Where are the accommodations in }\end{array}$ & $\begin{array}{l}\text { What are the accommodations available? What } \\
\text { is their classification and categorization? }\end{array}$ \\
$\begin{array}{l}\text { Whe city located? What is their facilities located } \\
\text { classification? What are their }\end{array}$
\end{tabular}


Tarmiji Masron, Azizan Marzuki, Badaruddin Mohamed \& Norizawati Mohd Ayob

Conceptualise Tourism Support System through Web-Based GIS for Collaborativetourism Planning

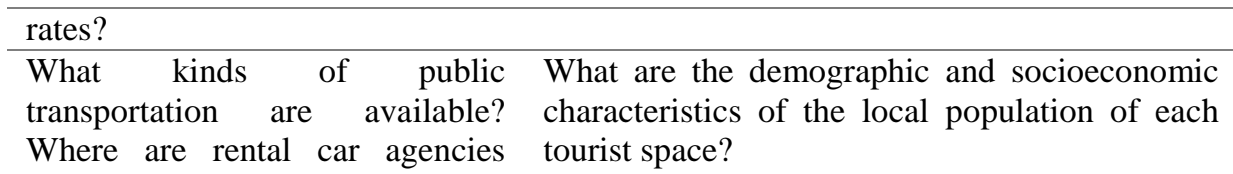

located?

Where are the cultural/natural What are some plans, programs and projects amenities located? What is their that would help stimulate tourism activity. operating schedule? What is the cost to attend?

What attractive places are near What infrastructure services are in current and my hotel? potential tourist areas? Which is the service quality?

Where are the banks? Where is What is the tourist demand for attractive places, the police station? Where is the tourist equipment, and services? hospital?

Where are the shopping centers? Which public and private institutions are available and competent in tourism planning?

Source: Duran, Seker \& Shrestha, 2004

Interestingly, public participation has become one of the main source to build the web base GIS as a medium to promote tourism products. There are a lot of web based GIS created for that purpose, one of which include Nigeria's Oyo State Web based GIS tourism portal. Data collection for the project was done using the primary and the secondary method, with primary data collected through the interviews with state tourism board, manager of the tourist centers, Ministry of Information, Oyo State and the department of survey, the Oyo State Ministry of Lands and the Housing and also GIS expert from the Federal School of Survey. The Oyo State Web based GIS were designed using a combination of both the server-side and client-side applications which is hybrid architectures (Figure 5). Spatial component (database) was developed using ESRI's Arc View software, and the project also collects the data attributes (image, text, etc.) from various sources and links it to their respective spatial features. Oyo State Tourism web based GIS homepage contained five main icons - tourist attraction (ecological, cultural, modern features), GIS (internet and desktop GIS), tourism facilities (hotel, location and other services), contact us and about Oyo State. 
PLANNING MALAYSIA

Journal of the Malaysia Institute of Planners (2014)

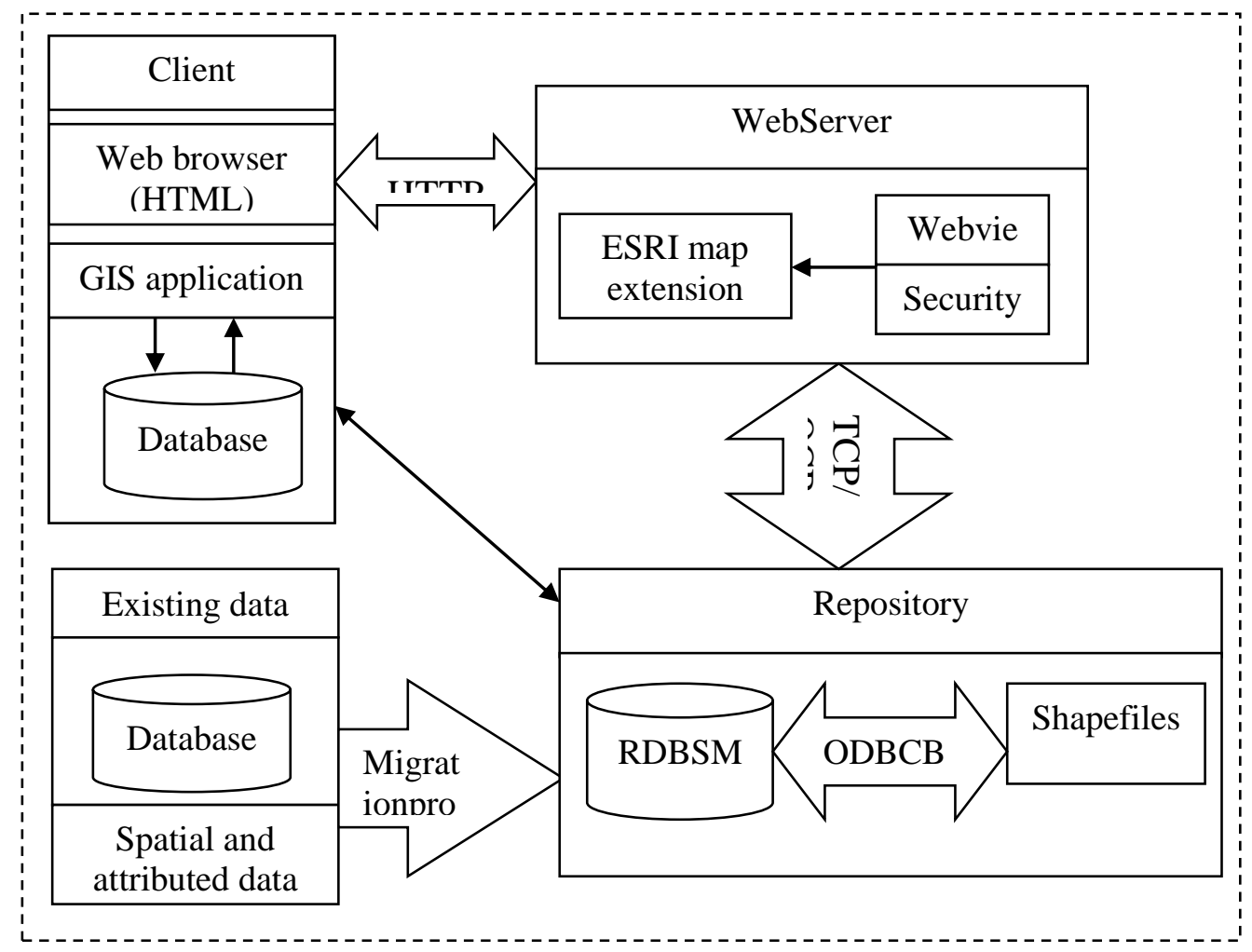

Figure 9: Hybrid Architecture for Web based GIS in Oyo State Tourism

Sources: Fajuyigbe, Balogun, \& Obembe, 2007

Markos (2012) also developed a web GIS for tourism development of Bahir Dar town in Ethiopia to provide spatial and non spatial tourism information for tourist purposes. The web GIS development cycle starts with requirement analysis and ends with the implementation of the web GIS system. In requirement analysis, there are two critical pieces of information, first being a list of functions that is needed and second, a master list of available attractions. The project was developed using three tier software architecture with server-side solution (Figure 6). The web GIS contain the information about tourist spots, hotels, banks, shopping markets, health centers, transport destinations, main roads and information about Lake Lana (Figure7). 
Tarmiji Masron, Azizan Marzuki, Badaruddin Mohamed \& Norizawati Mohd Ayob

Conceptualise Tourism Support System through Web-Based GIS for Collaborativetourism Planning
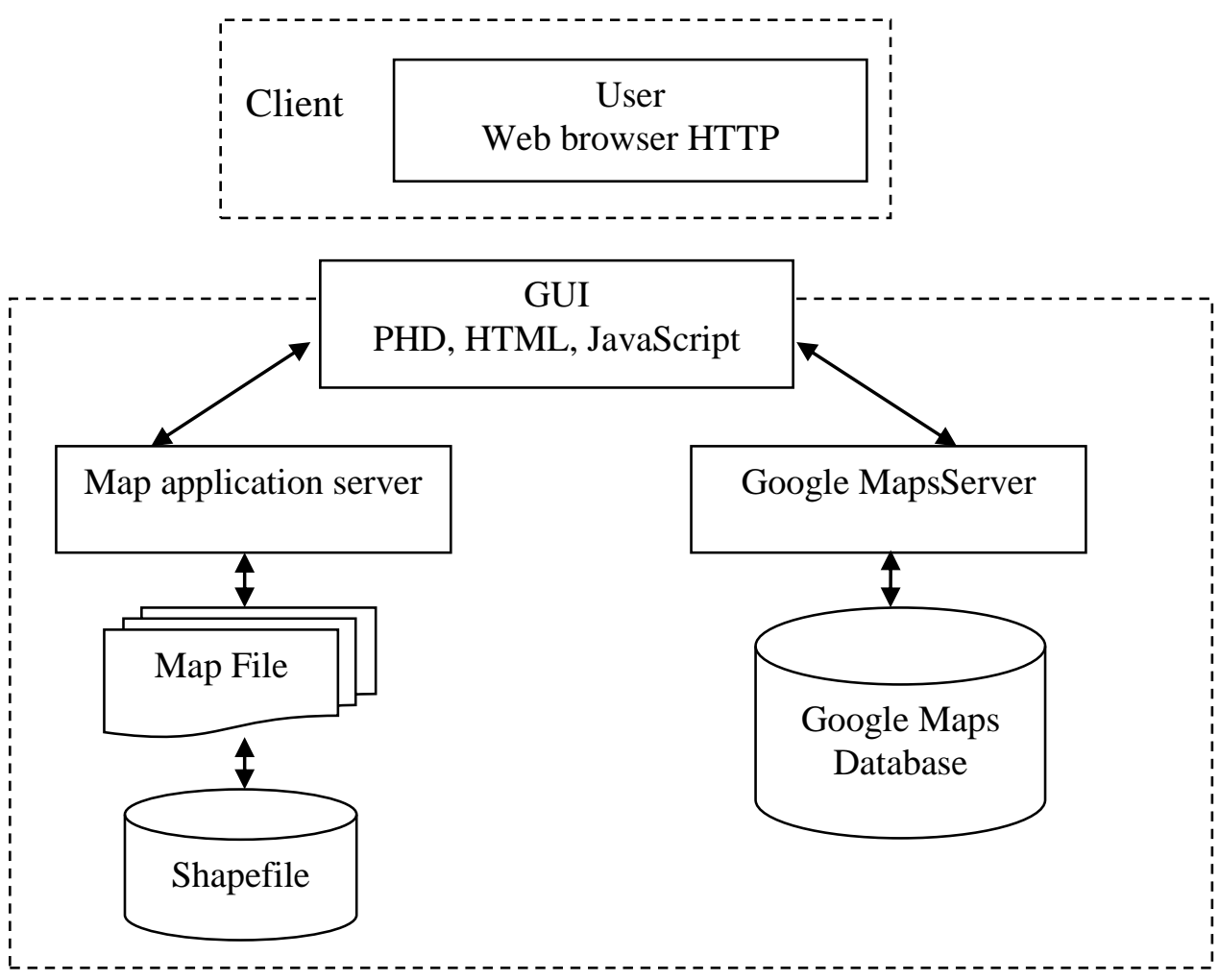

Figure 10: Bar Dar Town Web based Architectures 
PLANNING MALAYSIA

Journal of the Malaysia Institute of Planners (2014)

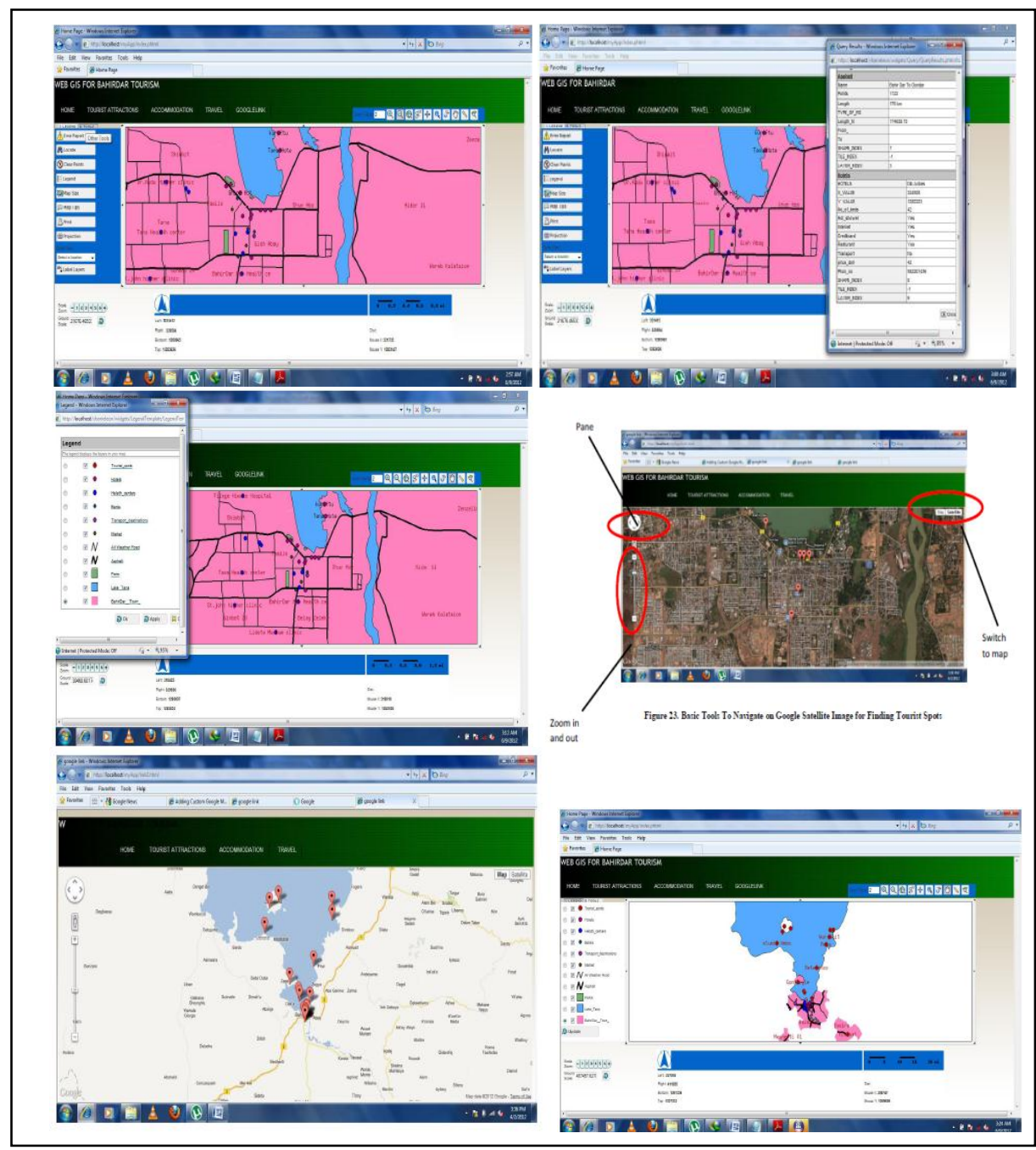

Figure 11: Application and Interface in Bar Tar Town Web GIS

Source: Markos, 2012

The web based GIS in Zaozhuang, China was also developed for tourism information and tourism-related products such as transportation, shopping, accommodation and catering and other ancillary travel information for tourist to plan their itinerary. The system has beeen divided into two modules - tourism application subsystem and administrator management subsystem which includes four different layers: data layer, service layer, basic information layer and finally an application layer (Figure 12). 
Tarmiji Masron, Azizan Marzuki, Badaruddin Mohamed \& Norizawati Mohd Ayob

Conceptualise Tourism Support System through Web-Based GIS for Collaborativetourism Planning

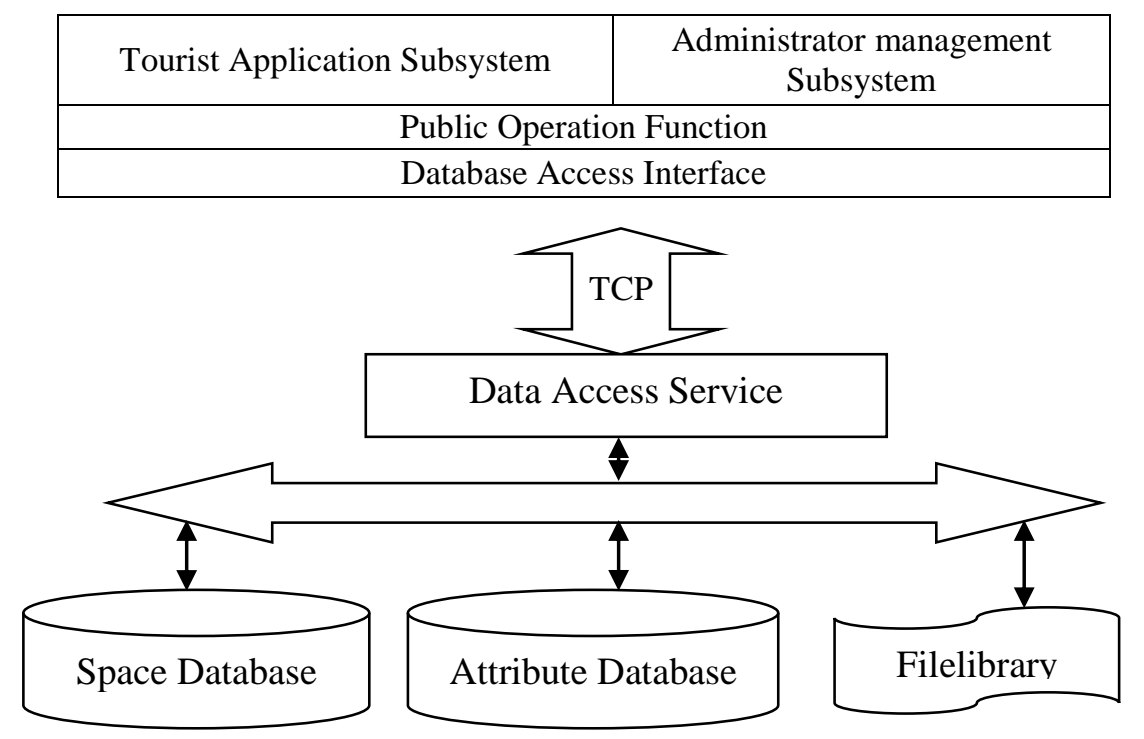

Figure 12: The structure of Zaozhuang Tourist Information System

This is a very capable system with an impressive array of functions of the map view and search requirements as follows - spatial information measurement; statistical analysis and statistical mapping display; Multiple Window Linkage; typical feature dimension; displaying the scenic spots, optimal path analysis; dynamic and interactive features, prediction function and system management, data maintenance and update (Yan \& Wang, 2012).

Malaysia's Langkawi Island web GIS was also developed using client-server application or known as hybrid solution architecture using three tier GIS web based system (Figure 9). The web is hosted on the server, which delivers web content requested by the client hardware. The server requires certain software to produce the web content requested by the client, while the client requires software to display the web content. The software included the ArcGIS 10.1 for Server, PostgreSQL 9.0, Internet Information Service (IIS) and web browser. The development of web GIS of Langkawi Island is not performed via the server but through another computer which requires the ArcGIS for Desktop, ArcGIS, Viewer for Flex - Application Builder and Adobe Flash Builder 4.6 and ArcGIS API for Flex. The public user does not need any GIS to access GIS function in the Langkawi Island Web GIS. In fact, the web GIS was designed for any user, with or without GIS knowledge, as it just requires simple software which has a web browser and flash player only. 
PLANNING MALAYSIA

Journal of the Malaysia Institute of Planners (2014)

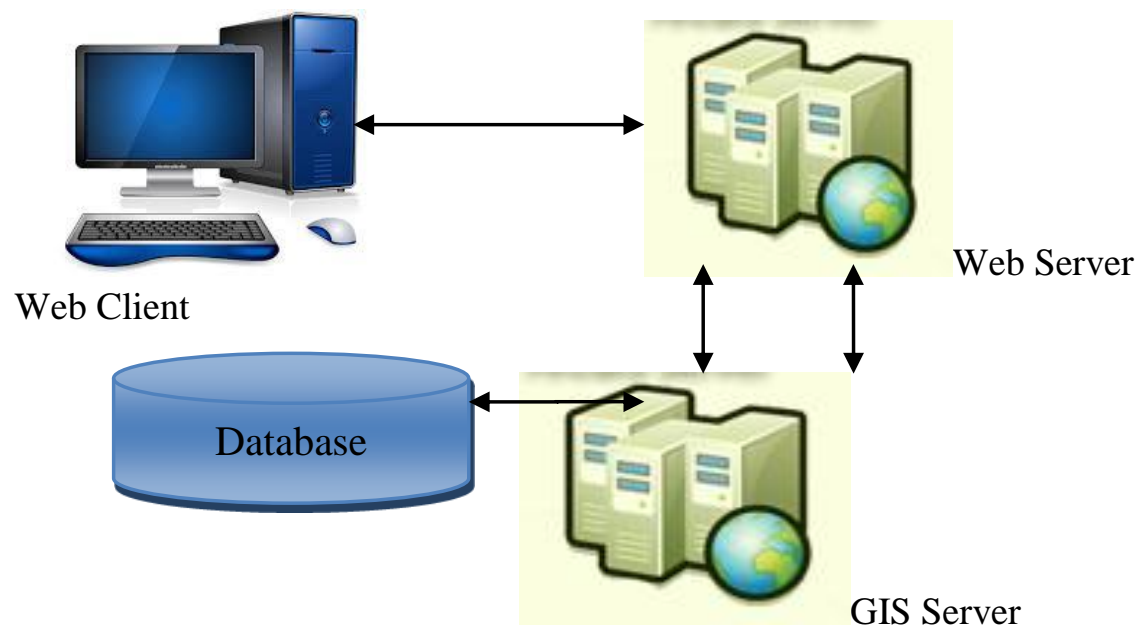

Figure 13: Architecture of Three Tier Langkawi Island Web GIS

Several functions in the Langkawi web GIS include navigation tool (zoom in, zoom out, pan, zoom slider, zoom to full extent, previous and next extent, and move up/down/left/right); map switcher (between topographic map and satellite imagery) and map functions (Figure 10). There are five function categories in the map function menu, with each having their own submenu (Table 2).

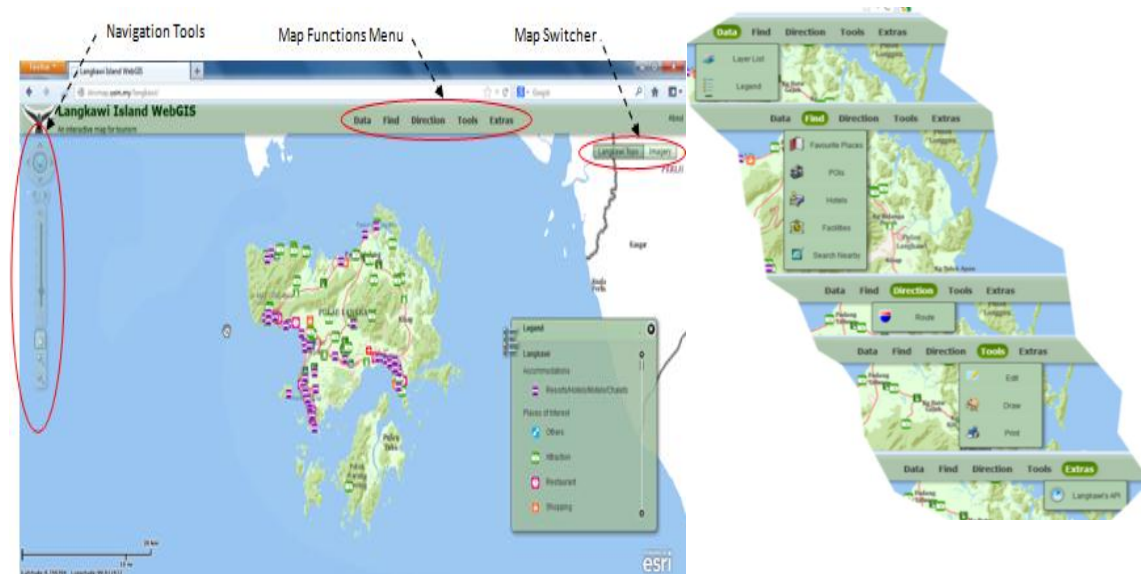

Figure 14: Langkawi Island Web GIS Functions

Table 12: Sub menu in Map Function for Langkawi Island Web GIS No Menu Sub menu Description 
Tarmiji Masron, Azizan Marzuki, Badaruddin Mohamed \& Norizawati Mohd Ayob

Conceptualise Tourism Support System through Web-Based GIS for Collaborativetourism Planning

\begin{tabular}{|c|c|c|c|}
\hline \multirow[t]{2}{*}{1} & Data & Layer List & $\begin{array}{l}\text { This submenu shows layers of data available in the web GIS. } \\
\text { The currently available layers are 'Langkawi' (i.e. Location of } \\
\text { accommodation, shopping, and tourist attractions), 'More } \\
\text { Langkawi Data' (i.e. Land Use of Langkawi in } 2006 \text { and } \\
\text { Development Block in Langkawi), and Langkawi Annual API } \\
\text { (i.e. Annual Pollution Index within Kuah town). 'Langkawi' } \\
\text { layer is shown by default, while the other layers are hidden by } \\
\text { default. 'More Langkawi Data' layer can be shown manually } \\
\text { by the user, while 'Langkawi Annual API' will be shown } \\
\text { automatically when 'Langkawi's API' function is executed. }\end{array}$ \\
\hline & & Legend & $\begin{array}{l}\text { This submenu turns the legend window ON or OFF. The } \\
\text { legend window is ON by default. }\end{array}$ \\
\hline \multirow[t]{5}{*}{2} & Find & $\begin{array}{l}\text { Favorite } \\
\text { Places }\end{array}$ & $\begin{array}{l}\text { This submenu lists, bookmark of famous tourism areas in } \\
\text { Langkawi. When a bookmark is clicked, the map will zoom in } \\
\text { the corresponding area. }\end{array}$ \\
\hline & & POIs & $\begin{array}{l}\text { This function searches for places of interest based on user } \\
\text { input. A user can choose between searching by name or by } \\
\text { attributes (type or location) of the place. }\end{array}$ \\
\hline & & Hotels & $\begin{array}{l}\text { This function searches for accommodations based on user } \\
\text { input. A user can choose between searching by name or by } \\
\text { attributes (type or location) of the accommodation. }\end{array}$ \\
\hline & & Facilities & $\begin{array}{l}\text { This function searches for public facilities, such as bank and } \\
\text { petrol station, based on user input. A user can search by } \\
\text { attributes (type or location) of the place. }\end{array}$ \\
\hline & & $\begin{array}{l}\text { Search } \\
\text { Nearby }\end{array}$ & $\begin{array}{l}\text { This function searches for accommodations, facilities, and } \\
\text { place of interest within a certain distance from a point } \\
\text { location in the map. A user specifies the distance and clicks } \\
\text { any location in the map to do the search. }\end{array}$ \\
\hline 3 & Direction & Route & $\begin{array}{l}\text { This function finds the shortest or the quickest route to travel } \\
\text { from one starting point to one or more (up to 9) destinations. } \\
\text { The function has options to find the best sequence to visit the } \\
\text { points as well as the route to return to starting point. Users } \\
\text { pick the points by clicking on the map. }\end{array}$ \\
\hline \multirow[t]{3}{*}{4} & Tools & Edit & $\begin{array}{l}\text { This function allows users to point data of accommodations, } \\
\text { and tourist attractions. Users can also use the function to edit } \\
\text { attributes of existing points. The editing results are subjected } \\
\text { to validation by the data administrator before they are shown } \\
\text { in the WebGIS. }\end{array}$ \\
\hline & & Draw & $\begin{array}{l}\text { This function allows user to draw lines or polygons to } \\
\text { measure distance or area in the map. }\end{array}$ \\
\hline & & Print & $\begin{array}{l}\text { This function allows a user to print the current view of the } \\
\text { map. }\end{array}$ \\
\hline 5 & Extras & $\begin{array}{l}\text { Langkawi's } \\
\text { API }\end{array}$ & $\begin{array}{l}\text { This function displays a time animation of the Average } \\
\text { Annual Pollution Index over the year of } 2000 \text { to } 2010 \text {. }\end{array}$ \\
\hline
\end{tabular}

The Langkawi Island WebGIS utilizes many spatial data to present information as an interactive online map. The main data used are stored as feature classes in a geodatabase and it includes the data of road networks, 
accommodations, tourist attractions, facilities and places of interests in Langkawi Island. Each attribute data was provided with explanations and image. Figure 11 shows some application of the Langkawi Island web GIS interface.

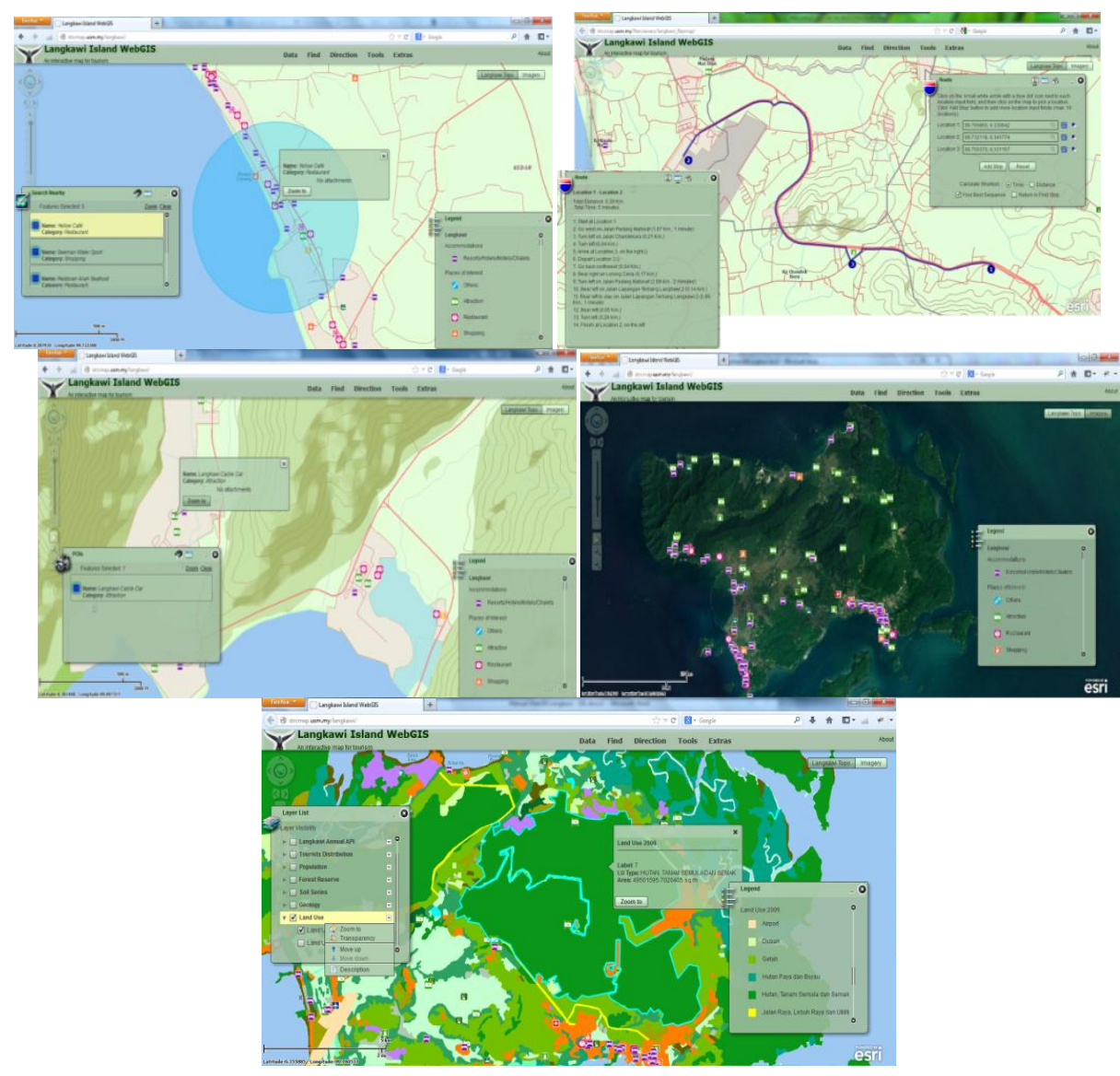

Figure 15: Langkawi Island Web GIS Application and Interface

The Langkawi Island Web GIS is a web site which provides tourism related information about Langkawi Island in the form of interactive maps with Geographic Information System capabilities. In contrast with the usual website, this website presents its information content by using maps more than a text description. A visitor of the Langkawi Island Web GIS can zoom in or out the map and pan the map (or, scroll the map) to view a location. Accommodations, sightseeing attractions, shops, restaurants, and public 
Tarmiji Masron, Azizan Marzuki, Badaruddin Mohamed \& Norizawati Mohd Ayob

Conceptualise Tourism Support System through Web-Based GIS for Collaborativetourism Planning

facilities are shown as different symbols which can be clicked to view their related information.

Since the web site has GIS capabilities, visitors can do a number of GIS operation on the map, which are not possible with ordinary websites. For example, visitors can search for an accommodation or sightseeing attractions based on keywords, or the visitor may find public facilities available within a given distance from their hotel. Another example of a useful GIS function allows the Web GIS in finding the shortest or quickest route from one location to other location (up to 9 destinations). The Web GIS shows the best route on the map with detailed driving directions to travel along the route. This system also allows public participation as an information supply. The edit function in this web GIS allows users to add point features (objects) or edit information (attribute data) of existing point features in the Web GIS. A point feature may represent an accommodation or a place of interest. The new point features (objects) or changes in information of existing point feature, however, will not appear in the web GIS before they are verified by the GIS Administrator. Only valid point features and information are displayed in the web GIS.

A tourism industry plays an important role for many local economies particularly in developing countries and small island states (Liu \& Sharina, 2011). Due that, more information was requiring to make sure it good enough to compete with other destination. The Langkawi Web GIS is not only useful for tourists or potential tourists. The web site also provides maps and data that can benefit researchers or other people. For example, the web visitor can activate land use layer to view the land use map of Langkawi. The Web GIS also has a time animation function which shows changes in map over time, such as the change in the Air Pollution Index. In summary, the Langkawi Island Web GIS provides a novel and interesting way to present information about Langkawi Island which encompassing historical sites, geological wonders, beautiful natural landscapes and a wealth of local culture and traditions (Rahimah, Halimanton Saadiah \& Ibrahim, 2011).

There are a lot of web based GIS being developed for the tourism industries, but different objectives of the projects require different design, software and architectures. Firstly is the difference in the architecture system itself. The implementation of hybrid architecture is more powerful than using specific server-side or client-side architecture as hybrid architectures are more public friendly allowing the user to use both (server and client) design techniques to access the GIS on the internet. Secondly, is about the level of public participation. Public participation and involvement can be obtained in the first phase (surveys and interviews) while also allowing the 
public to become sources of information through the edit application over the web based portal.

\section{CONCLUSION}

Application of web GIS as a medium to provide spatial and non-spatial tourist information is fast becoming the current trend. The application of web based GIS like Google Map, Yahoo Map and GlobeXplore provides a new generation of interfaces and expanded the ways in which travel information can be accessed. Geographical information accounted for nearly half of travel information search queries (Jansen, Ciamacca, \& Spink, 2008). Further, there are many web based GIS developed by organizations, governments, NGOs, researchers, individuals, tourism stakeholders and others in a plethora of ways to promote tourism industries in their countries. The use of web based tourism information system is growing significantly and is predicted to maintain its growth trajectory in the future with the real possibility of ultimately creating the whole tourism business as an internet based business.

However, to create the web based GIS are a complicated task and require expert knowledge to visualize the architecture and to enable the web GIS system. Developing a web GIS is beyond simply using the appropriate hardware and software. The understanding about equipment analysis, conceptual design, acquisition of GIS hardware and software, database design and construction, integration of the web GIS system and web GIS use and the implementation required in ways to develop the massive web based GIS for collaborative planning and public participation in tourism industries, all feature prominently in the creation of a progressive web based system. The high level of information and functionality in web based GIS is a clear reflection of the complexity of the architecture inside web based GIS.

\section{ACKNOWLEDGEMENT}

This paper is part of the Research University Grant for Cluster (RUC) 1001/PTS/8660014. Tourism Decision Support System, Sustainable Tourism Research Cluster USM, Malaysia.

\section{REFERENCES}


Tarmiji Masron, Azizan Marzuki, Badaruddin Mohamed \& Norizawati Mohd Ayob

Conceptualise Tourism Support System through Web-Based GIS for Collaborativetourism Planning

Ali, A.A. (2006). Knowledge Cities: Examining the Discourse Smart Villages, Internet Cities or Creativity Engines. Journal of the Malaysian Institute of Planners, 4, $31-48$

Al-Kodmany, K. (2002). GIS and the artist: shaping the image of a neighborhood through participatory environmental design. In Craigh, W., Harris, T. \& Weiner, D., Community Participation and Geographic Information Systems, 320-329.

Avdimiotis, S., \& Christou, E. (2004). GI.S Applications in Tourism Planning: A Tool For Sustainable Development Involving Local Communities, Journal of Environmental Protection \& Ecology, 5 (2), 457-468.

Banger, S. (2002, May 10). Geospatial World. Retrieved May 1, 2014, from Integrating GIS with web for public participation: http://www.geospatialworld.net/Paper/ Technology/ArticleView.aspx?aid=1818

Belay, A. (2005). Internet-GIS: An application to Real Estate and Housing management in the City Government of Addis Ababa (CGAA). Addis Ababa: Addis Ababa University.

Brody, S. D., Godschalk, D. R., \& Burby, R. (2003). Participation in Plan Making: Six Strategic Planning Choices, Journal of the American Planning Association, 69 (3), 245-264.

Brown, G. G., \& Reed, P. (2009). Public Participation GIS: A New Method for Use in National Forest Planning, Forest Science, 55 (2), 166-182.

Carver, S., Evans, A., Kingston, R., \& Turton, I. (2002). University of Leeds. Retrieved April 31, 2014, from Virtual Slaithwaite: a web based public participation 'Planning for Real' system: http://www.geog.leeds.ac.uk/papers/99-8/

Casey, L., \& Pederson, T. (2002). Mapping Philadelphia's neighborhoods, Community Participation and Geographic Information System, 65, 65-76.

Chang, G., \& Caneday, L. (2011). Web-based GIS in tourism information search: Perceptions, tasks, and trip attributes, Tourism Management, 32, 1435-1437.

Devaraju, A., Nanna, S. H., \& Shahrin, S. (2007). Building of the Enabled Web-Based GIS Participation System: A Tool to Enhance Community Participation in City Development Plan. The 2nd International Conference on Advances in Information Technology (IAIT2007). Thailand.

Devictor, V., Whittaker, R. J., \& Beltrame, C. (2010). Beyond scarcity: citizen science programmes as useful tools for conservation biogeography, Diversity and Distributions, 16, 354-362.

Duran, E., Seker, D. \& Shrestha, M. (2004). Web Based information System for Tourism Resorts: A Case Study for Side/ Manavgat. Geo-Imagery Bridging Continents XXth ISPRS Congress, (pp. 12-23). Istanbul.

Fajuyigbe, O., Balogun, V., \& Obembe, O. (2007). Web-Based Geographical Information System (GIS) for Tourism in Oyo State, Nigeria.Information Technology Journal, 6 (5), 613-622.

Gillavry, E. (2000). Cartographic aspects of Web GIS-software. Utrecht: Department of Cartography Utrecht University.

Godschal, D., Parham, D., Porter, D., Potapchuk, W., \& Schukraft, S. (1994). Pulling Together: A Planning and Development Consensus Building Manual. Washington, D.C: Urban Land Institute. 
Gu, H., \& Ryan, C. (2008). Place attachment, identity and community impacts of tourism: The case of a Beijing Hutong, Tourism Management, 29 (4), 637-647.

Healey, P., McNamara, P., Elson, M., \& Doak, A. (1988). Land Use Planning and the Mediation of Urban Change. Cambridge: Cambridge University Press.

Hopkins, L. D., Twidale, M. \& Pallathucheril, V. G. (2004). Interface devices and public participation. Proceedings of the 3rd Annual PPGIS Conference, Madison, Wisconsin, July 2004, 71-83

Ingensand, J, \& Golaym, F. (2010). Task-oriented usability evaluation of a Web-GIS for real world community, URISA Journal, 21 (1), 41-53

Jansen, B., Ciamacca, C., \& Spink, A. (2008). An Analysis of Travel Searching on th Web. Journal of Information Technology and Tourism, 10, 101-118.

Kingston, R. (2007). Public Participation in Local Policy Decision-making: The Role of Web-based Mapping, The Cartographic Journal, 44 (2), 138-144.

Kingston, R., Carver, S., Evans, A., \& Turton, I. (2000). Web-based public participation geographical information systems: an aid to local environmental decisionmaking. Computers, Environment and Urban Systems, 24, 109-125.

Lee, A. T. (2000). Web site usability, usefulness, and visit frequency. Proceedings of Human Factors and Ergonomics Society Annual Meeting, San Diego, California, July-August, 2000, 404-407

Liu, O.P \& Sharina, Abd Halim. (2011). Planning for Heritage Tourism: The Case of Langkawi Geopark. Journal of the Malaysian Institute of Planners, 121-144

Loghi, C. (2008). Usages of the internet and e-tourism. Towards a new economy of tourism. IDEAS RePEC, 1-21.

Markos, A. (2012). Web GIS for Tourism Development of Bahir Dar Town and Its Surroundings, Ethiopia. Addis Ababa: Addis Ababa University.

Meng, Y \& Malczewski, J. (2010). Web-PPGIS Usability and Public Engagement: A Case Study in Canmore, Alberta, Canada. URISA Journal, 22 (1), 55-64

McAdam, D. (1999). The Value and Scope of Geographic Inroformation System in Tourism Management, Journal of Sustainable Tourism, 7 (1), 77-92.

Nuohua, J., Juustila, A., Raisanen, T., Kuutti, K., \& Soudunsaari, L. (2008). Exploring Web-based Participation Methods for Urban Planning. Professional Developers Conference, Los Angeles, 74-277

Peng, Z., \& Tsou, M. (2003). Internet GIS: Distributed Geographic Information services for the internet and wireless networks. New Jersey: John Wiley and Sons.

Peng, Z.-R. (2001). Internet GIS for public participation. Environment and Planning B, Planning and Design, 28, 889 - 905.

Rahimah, A.Z, Halimanton Saadiah, H \& Ibrahim, Komoo. (2011). Geopark for Heritage Conservation: A need for Integrated Planning and Management. Journal of the Malaysian Institute of Planner, 25-38

Sadagopan, G. D. (2000). Web-Based Geographic Information Systems: Public Participation in Virtual Decision Making Environments. Virginia: Virginia Polytechnic Institute and State University.

Schoeder, P. (1997). GIS in public participation settings. University Consortium for Geographic Information Science (UCGIS) 1997 Annual Assembly and Summer Retreat. Bar Harbor, $\quad$ Maine, June 15 - June 21, 1997 
Tarmiji Masron, Azizan Marzuki, Badaruddin Mohamed \& Norizawati Mohd Ayob

Conceptualise Tourism Support System through Web-Based GIS for Collaborativetourism Planning

Shaig, A. (2001). An Overview of Web based Geographic Information Systems. - The 13th Annual Colloquium of the Spatial Information Research Centre. Dunedin: University of Otago.

Shanker, D. (2008). ICT and Tourism: Challenges and Opportunities. Conference on Tourism in India - Challenges Ahead. Kerala: The Indian Institute of Management Kozhikode, 50-58

Sidlar, C \& Rinner, C. (2007). Analyzing the usability of an argumentation map as a participatory spatial decision support tool, URISA Journal, 19 (1), 47-55

Ventura, S., Niemann, B., Sutphin, T., \& Chenowith, R. (2002). GIS-enhanced land-use planning. Community Participation and Geographic Information Systems. In Craig, W.J, Harris, T.M \& Weiner, D. Community Participation and Geographic Information Systems, 113-124.

Werthner, H., \& Klien, S. (1999). Information Technology and Tourism: A Challenging Relationship. Vienna: Springer.

Wilkinson, P. F. (2007). Community destination management in developing economies, Annals of Tourism Research, 32 (2), 549-550.

Yaakup, A., Jama'an, J., Abu Bakar, Y., \& Sulaiman, S. (2001). Web-based GIS for public participation in urban planning and management case study: Klang Valley region. Proceedings Asia GIS 2001 Conference, (pp. 1-8). Tokyo.

Yan, X., \& Wang, Y. (2012). Development of Zaozhuang Tourism Information System Based on WebGIS, International Journal of Computer Science Issues, 9 (6), 249-252. 